\title{
FRANCISCO GINER Y ADOLFO POSADA, PRECURSORES DE LA SOCIEDAD DE NACIONES
}

\author{
DELIA MANZANERO ${ }^{1}$ \\ Universidad Pontificia Comillas \\ (Madrid)
}

\begin{abstract}
RESUMEN: El presente artículo expone las contribuciones al proceso de formación de la Sociedad de Naciones que, desde los presupuestos sociológicos y jurídicos surgidos en las ideas ilustradas del filósofo Krause, fueron proyectadas y representadas por dos eminentes juristas krausistas españoles, Giner y Posada. En primer lugar, analizaremos la influencia de la tradición teleológica de la Interessenjurisprudenz en la filosofía del derecho krausista, y la función de esta corriente iusfilosófica como movimiento modernizador y emancipador del formalismo positivista imperante de la época. En segundo lugar, profundizaremos en los principios básicos de la teoría sociológico-jurídica krausista que han constituido un factor de europeización de primer orden, para lo cual se repasarán sus más acerbas críticas a las doctrinas europeas del nacionalismo imperialista. Por último, nos ocuparemos del papel del krausismo en la promoción y defensa los Catorce Puntos de Wilson y la Sociedad de las Naciones, y sus apreciaciones sobre lo que debería ser objeto de impugnación en materia de derecho internacional.
\end{abstract}

PALABRAS CLAVE: Krausismo, lusnaturalismo, Internacionalismo, Sociedad de Naciones, Derechos Humanos.

\section{Francisco Giner and Adolfo Posada, precursors of the League of Nations}

\begin{abstract}
This paper presents the contributions to the process of formation of the League of Nations which, from sociological and legal premises present in the enlightened ideas of the German philosopher Krause, were designed and represented by two eminent Spanish Krausist jurists, Giner and Posada. First, we will analyse the influence of the teleological tradition of the Interessenjurisprudenz in Krausist legal philosophy, and the function of this iusphilosophical trend as a modernising and emancipating movement from the prevailing positivist formalism of the time. Secondly, we will delve into the basic principles of the Krausist sociological and legal theory which have been a major factor of Europeanisation, for which we will review his most scathing criticism to the European doctrines of imperial nationalism. Finally, we will address the role of Krausism in the promotion and defense of Wilson's Fourteen Points and the League of Nations, and its views on what should be subject to contestation in terms of international law.
\end{abstract}

KEY WORDS: Krausism, lusnaturalism, Internationalism, League of Nations, Human Rights.

1 Esta investigación se inscribe dentro del proyecto de investigación: «Fundamentos y desarrollo de la idea krausista de Europa: universalismo, internacionalismo, educación y cultura» (Proyecto de investigación I+D+i reference: FFI2011-23682, 2012-2015) de la Universidad Pontificia Comillas, dirigido por Ricardo Pinilla Burgos y financiado por el Ministerio de Economía y Competitividad. 


\section{INTRODUCCIÓN}

Tal y como se anuncia en el título de este trabajo, vamos a centrar nuestro estudio en las contribuciones de la teoría sociológica y jurídica del krausismo español al proceso de construcción de Europa, concretamente, a la formación de la Sociedad de Naciones, si bien, antes de entrar en ese tema, conviene constatar en este apartado preliminar que el krausismo, al mismo tiempo, también contribuyó sustancialmente a la europeización y modernización de la Ciencia en España.

Lo primero que habría que indicar es que la proyección de la filosofía jurídica y sociológica krauseana tuvo en España el vigor y la forma de todo un proyecto de renovación nacional. Las propuestas krausistas fueron un esfuerzo por contribuir al proyecto de conseguir una España más europea y universal que, en coherencia con la teoría social krausista, no se limitara a una mera preocupación por lo nacional, sino que fuera totalmente solidaria con la democracia y el pleno desarrollo cultural y material en otros países. Ello se aprecia especialmente en el papel que tuvieron algunos krausistas como Adolfo Posada o Giner en la formación de la Sociedad de Naciones y en su interpretación de los Catorce puntos de Wilson, a cuyas virtudes -y también limitaciones e insuficiencias-, se refirió Posada en la traducción y comentario de la obra de W. Wilson al español que comentaremos en este ensayo.

Procedamos pues a hacer una revisión de esta tradición del pensamiento universalista europeo, iniciada por el conocido padre del krausismo, Karl Christian Friedrich Krause, que se concretó y tomó cuerpo en los tratados de derecho de krausistas europeos como Ahrens y Tiberghien, y que, como tendremos ocasión de explicar, tuvo una especial intensidad y desarrollo en krausistas españoles como Francisco Giner y Adolfo Posada².

\section{REFLEXIÓN KRAUSISTA SOBRE LOS FINES DEL DERECHO}

Durante la Edad de Plata española fueron numerosos los krausistas españoles que mantuvieron contactos serios y profundos con el estado del pensamiento

\footnotetext{
2 Vid. un encuadre de la filosofía krausista en el contexto europeo y la modernidad: Álvarez Lázaro, P. (ed. lit.), Ureña, E. M., (ed. lit.), La actualidad del krausismo en su contexto europeo, España, Editorial Parteluz, Fundación Duques de Soria, Universidad Pontificia Comillas, Col. ILKM, 16, 1999. Ureña, E. M. «El krausismo como filosofía de la Modernidad», en: Hugo Biagini (Comp.), Orígenes de la democracia argentina. El trasfondo krausista, Buenos Aires, Fundación Friedrich Ebert - Ed. Legasa, 1989, pp.163-174. SÁnchez Cuervo, A. «Las ilustraciones del krausismo», en: Cuaderno de historia de las ideas, vol. 8, 2007, pp. 151-163.
} 
en Europa ${ }^{3}$ y con las corrientes jurídicas europeas modernas ${ }^{4}$; de ello se hizo eco, por ejemplo, Adolfo Posada con su traducción de la obra de Ihering ${ }^{5}$, una obra con la que se propiciaba una progresiva emancipación del formalismo positivista imperante de la época. Como es bien sabido, Rudolf Von Ihering representa una nueva vía antiformalista, que fue muy fecunda y apreciada por los juristas del krausismo español. Su adscripción a la tradición teleológica de la Interessenjurisprudenz, que caracterizaba al derecho como algo que existe para garantizar y proteger los intereses de la vida, para realizar determinados fines y valores, tuvo una gran repercusión en el movimiento iusfilosófico del krausismo.

La doctrina de los fines es pues de suma importancia para la teleología jurídica krausista. Lo primero que debemos advertir en la concepción krausista del fin, es que lejos de ser algo exterior al sujeto, a la institución o a su relación misma, el fin es, en expresión de Ahrens, la esencia interna de la cosa recibida en el pensamiento tal y como tiende a realizarse en la vida. En otras palabras, el fin es la naturaleza de la cosa misma y lo que le procura su fuerza más íntima y su proyección. Aquí conviene advertir que la noción de «naturaleza» krausista no parte de asumir acríticamente postulados ahistóricos o deterministas, sino que viene a subsanar los excesos del iusnaturalismo puramente teórico y dogmático propios de la filosofía del derecho del siglo xvIII, que, aún compartiendo con el krausismo algunos argumentos, reducía el derecho natural al supuesto de un estado humano perfecto y formal ante el que los krausistas se mantuvieron alerta:

«También el Derecho natural vislumbró esta idea, aunque confusamente: pues trató de deducir el Derecho de la naturaleza del hombre. Erró tan sólo al creer que podía alcanzar el conocimiento de ésta, a partir de un "estado natural" o mediante algunos conceptos antropológicos superficiales o con el

3 Remitimos a las fuentes epistolares con testimonios que muestran la poderosa proyección internacional que tuvo el movimiento intelectual europeísta krausista: UREÑA, E. M., Vázquez-Romero, J. M. (eds.), Giner de los Ríos y los krausistas alemanes correspondencia inédita, Con introducción, nota e índices. Presentación de José Manuel Pérez-Prendes MuñozArraco, Madrid, Universidad Complutense de Madrid, 2003. Ureña E. M., Cincuenta cartas inéditas entre Sanz del Río y krausistas alemanes (1844-1869). Madrid: LKM, n. ${ }^{\circ}$ 6, 1993.

4 Este contacto con las principales universidades europeas y americanas no se entiende sin la importante función de la Junta para Ampliación de Estudios e Investigaciones Científicas (JAE) y su política de pensionados en el extranjero: «sépase también cuántos filósofos académicos del Derecho se beneficiaron entre 1907 y 1936 de las becas de la Junta, con las que pudieron irse al extranjero, sobre todo a Alemania, a estudiar junto a los pensadores más punteros de la especialidad: por lo menos, Rivera Pastor, F., Ramos Sobrino, B., Recaséns Siches, L., Luño Peña, E., Legaz Lacambra, L., Corts Grau, J. o González Vicén, F.». Rivaya, B., «Historia política de la filosofía del Derecho española del siglo xx», en: DOXA, Cuadernos de Filosofía del Derecho, 32 (2009), ISSN: 0214-8676, p. 545.

5 Von Ihering, R., La lucha por el Derecho, Buenos Aires, trad. directa del alemán por Adolfo González Posada, Profesor de la Universidad de Madrid, Editorial Heliasta, 1974. (9ºd. con Prólogo de Leopoldo Alas (Clarín). Madrid: Lib. Gral de Victoriano Suárez, 1921 (1ª ed.). 
mero auxilio de fórmulas lógicas. Este Derecho natural se arruinó ciertamente; pero subsiste la necesidad formulada en su concepto fundamental $»^{6}$.

En su lugar, los krausistas exponen la evolución del ideal del derecho en la historia, como vida del derecho. Una vez más, Posada y Giner siguen en estos planteamientos a Heinrich Ahrens, quien a su vez cuenta con dos claros precursores, primero en Krause y luego en Stahl, cuyas teorías vinieron a aportar un mayor dinamismo a su exposición de la teleología jurídica y su defensa de la necesaria investigación de los fines en el Derecho:

«Aunque Kunze [...] opina que esta teleología jurídica, por la cual yo procuro trabajar, no es cosa nueva y que en cierto modo domina ya en la doctrina corriente, hay inmediatamente sólo dos teorías filosófico-jurídicas que hayan hecho resaltar la necesidad de la investigación de los fines del Derecho: primero, la de KRAUSE y después la de STAHL, que prefiere la expresión "determinación o destinación” (Bestimmung). La ciencia jurídica-positiva, tampoco es cierto que se halle dominada por la consideración de la finalidad; y si se vale de ella en ocasiones es sólo donde se halla demasiado perpleja en su concepción abstracta sin que jamás este principio teleológico haya sido aplicado conscientemente» ${ }^{7}$.

Ahrens distingue así en toda génesis o elaboración del Derecho un doble principio: el fundamento real (objetivo, la forma), y la causa eficiente (subjetiva, la materia, el fin ético $)^{8}$, la cual sólo puede hallarse en la total complexión de las relaciones éticas de la vida y en la consideración a los fines capitales que constituyen el fondo de las relaciones de la vida.

El objetivo de esta metodología basada en los fines y valores del Derecho no es sino analizar las posibilidades de una concepción normativa del Derecho que sea compatible con la Sociología y la Filosofía jurídica, que son las que, en efecto, pueden dotarle de plena legitimidad.

Esta transición de lo jurídico a lo sociológico, es retomada en los estudios sociológicos de Giner y Posada, por ejemplo, en el texto que reproducimos a continuación, en que puede apreciarse la utilización que hace Adolfo Posada de un Ihering un tanto krausistizado, cuyas implicaciones sociales y políticas para el derecho internacional trataremos de analizar con mayor detenimiento:

«La representación del Estado - y por ende, su idea- no se alcanza claramente abstrayendo de la realidad en que se produce el aspecto normativo, o de orden de la conducta humana. Esta abstracción, excelente quizá como método para determinar el Estado y definir su técnica — jurídica-, conducirá, por exceso de realismo abstracto, a la construcción puramente formal de una teoría del Estado, sin contenido, sin palpitaciones humanas, que son las que constituyen la esencia misma del Derecho. [...] Tienen, a nuestro juicio, profunda significación

6 Ahrens, H., Enciclopedia Jurídica o Exposición orgánica de la ciencia del derecho y del estado, versión directa del Alemán, con notas críticas y un estudio sobre la vida y obras del autor por Francisco Giner, Gumersindo de Azcárate y Augusto G. Linares. Madrid, t. I, 1878, p. 111.

7 Ahrens, H., Enciclopedia Jurídica, op.cit., t. III, 1880, p. 26.

8 Ahrens, H., Enciclopedia Jurídica, op.cit., t. I, 1878, pp. 107-ss. 
estas palabras de Ihering (La Lucha, cit., pág. 34): «El Derecho, que es, por un lado, la prosa, se traduce en la lucha por la idea en poesía, porque la lucha por el Derecho es, en verdad, la poesía del carácter». Aunque el Estado, como venimos sosteniendo (v. $1 .{ }^{1}$ edic. de este Tratado, I, 1893) — siguiendo la orientación de Krause, Ahrens, Giner-, se conciba como la expresión del orden jurídico, ni por un momento puede olvidarse que la razón y el objetivo inmediato y final —el contenido de las normas- son las necesidades, anhelos y aspiraciones humanos, y que la vida humana, con su dramatismo, ético, jurídico, estético, económico, religioso tiene su asiento y —escenario, su medio, en la naturaleza, que no es, en manera alguna, meramente receptora y pasiva, sino dinámica ${ }^{9}$.

Entender el concepto de Derecho como un mero sistema normativo nos conduce — según acaba de señalar Posada - al sometimiento de todos a formas de burocratización y de legalización formal que no permiten una libertad racional en términos sustantivos como la que promueven los krausistas, sino a modos de vida metódicos vacíos que conllevan un escepticismo frente al progreso y, en última instancia, a la pérdida de sentido de unas esferas que quedan escindidas de valor.

Una ciencia jurídica así entendida, carecería de sentido para los krausistas, pues no tendría respuesta para las únicas cuestiones que nos importan, las de qué debemos hacer y cómo debemos vivir. Esta crítica krausista a la ciencia jurídica positivista que se presenta como mera técnica y que no toma en consideración los sistemas de acción racional con respecto a fines ni se pregunta por el sentido que tiene el adoptarlos o asumirlos, entronca con las teorías críticas de las insuficiencias del proyecto moderno ${ }^{10}$.

«Otro tanto ocurre con la jurisprudencia, que se limita a constatar lo que es válido según las reglas del pensamiento jurídico, en parte estrictamente lógico y en parte vinculado por unos esquemas convencionalmente construidos. Su función es la de determinar cuándo son obligatorias determinadas normas jurídicas y determinados métodos para su interpretación. No responde, en cambio, a la cuestión de si debe existir el Derecho o de si deben establecerse precisamente esas normas y no otras; sólo puede indicar que si quiere obtenerse tal fin, el medio apropiado para alcanzarlo, de acuerdo con las reglas de nuestro pensamiento jurídico, es tal o cual norma» ${ }^{11}$.

9 Posada, A., Tratado de Derecho Político, Edición y Estudio Preliminar de José Luis Monereo Pérez. Granada: Editorial Comares, Colección: Crítica del Derecho, 2003, p. 139.

10 «Pero hay que admitir que ni los logros de la ciencia en sí mismos ni el perfeccionamiento de los métodos industriales se identifican directamente con el verdadero progreso de la humanidad. Es notorio que los hombres, pese al avance de la ciencia y la técnica, empobrecen material, emocional y espiritualmente. Ciencia y técnica son solo elementos de una totalidad social, y es muy posible que, a pesar de los avances de aquellas, otros factores, hasta la totalidad misma involucionen; que los hombres decaigan cada vez más y se vuelvan desdichados; que el individuo como tal sea anulado y que las naciones marchen hacia su propio infortunio». Horkheimer, M., Teoría crítica, trad. Edgardo Albizu y Carlos Luis. Buenos Aires-Madrid: Amorrortu Editores, 2003, p. 278.

11 Weber, M., «La ciencia como vocación», en: El político y el científico. Madrid: Alianza, 1988, pp. 208-211. 
Este texto de Weber se remite a una tradición de pensamiento que considera la lógica y la metodología como medios objetivos para la determinación del concepto del Derecho. Ahora bien, según la crítica krausista, debemos preguntarnos si es realmente suficiente esta aproximación metodológica para tener una visión completa de las ciencias, por ejemplo ¿Es posible entender la Medicina sin la deontología del corpus hipocrático? En la experiencia cotidiana, vemos con frecuencia que esa reflexión sobre la finalidad de la medicina y el tratamiento al paciente, se muestra tan necesaria como el uso del bisturí. Cabe preguntarse pues si este proceso de desmagificación o desencantamiento del racionalismo occidental que señala Weber y el consiguiente pesimismo por la tecnificación y la metodología logicista a la que la jurisprudencia queda reducida, tiene algún sentido que trascienda de lo puramente práctico. Para muchos autores la respuesta es ciertamente negativa.

Sin embargo, encontramos una línea de pensamiento en el krausismo que continúa esta tradición de pensamiento crítico hacia estos intentos de aislar ficticia y formalistamente el Derecho positivo vigente. Para los krausistas, detrás de todo Derecho positivo hay siempre una teoría de la justicia, es decir, una concepción del mundo, un sistema de valores jurídicos determinados, y negarse rotundamente a tratar de ello, supone fraccionar arbitrariamente esa totalización en que se expresa la realidad jurídica como realidad social.

En este sentido, nos ha parecido interesante recoger la crítica que Michael Villey hace a este reduccionismo del valor al hecho, a la eficacia, y a la consiguiente tecnocracia y a la especialización que trajo consigo el mundo contemporáneo, en una formulación que cobra renovado sentido para nuestro presente. Villey define la tecnocracia con la siguiente metáfora:

«Tecnocracia. Podría explicarse como una consecuencia de la dominación que ejercen las ciencias, que son únicamente ciencias de los medios. Nuestras eminencias intelectuales son maestros en la ciencia de los medios, de la eficacia, pero ciegos, a fuerza de no mirar, en todo lo demás y, sobre todo, en los fines. Ceguera contagiosa. Ellul compara nuestra sociedad a una potente locomotora, lanzada hacia adelante, bien alimentada, cuidada por especialistas cualificados, cada vez más fuerte, más "fiable" y más monstruosa. Pero del destino del viaje, nadie se preocupa. No sabríamos definir de un modo mejor al jurista contemporáneo. El jurista es un técnico que sabe de todo. El trabajo de almacenamiento de textos y "hechos sociales" acapara la vida de los estudiantes. La cuestión de los fines no existe. Se duda de que ella interese a un número importante de lectores. Y una de las causas del descrédito de la Filosofía del Derecho estriba en obstinarse en plantear esta cuestión ${ }^{12}$.

De acuerdo con esta metáfora tan ilustrativa de la locomotora que formula Villey, se nos ofrece esta visión de la generación de jóvenes juristas que salen de las universidades como meros tecnócratas, - -Villey los denomina social

12 Villey, M., Compendio de Filosofía del Derecho. Definiciones y Fines del Derecho, traducción de Jesús Valdés y Menéndez Valdés. Pamplona: Ediciones Universidad de Navarra, 1979, pp. 206-208. 
engineering-, de estudiantes que logran una gran inserción en el engranaje social a fuerza de someterse tan absolutamente a la sociedad, de centrar todo su interés en atender a su funcionamiento y en acelerar su marcha, en doblegarse a ella, y de dejar fuera de su óptica la justicia y la consideración de los fines. En este mismo sentido se pronuncia también Giner contra una educación vacía que deja en el olvido el cultivo de las cuestiones jurídicas fundamentales:

«La política entre nosotros era, sigue siendo aún, todo literatura: política de oradores, escritores, de poetas, de periodistas, de abogados... a veces también, de financieros, que sólo sirven por lo común para más embastecerla y depravarla. Los notables de nuestra política no son hombres de Estado, sino de Parlamento; no son gobernantes y estadistas, sino oradores; no obtienen su renombre y sus puestos por lo que hacen, sino por lo que dicen. Considérese ahora cuánto ha debido servir para alimentar este prurito de elocuencia una enseñanza vacía en el mismo molde. De las aulas de Derecho, a las "sociedades de hablar"; de éstas, a las Cámaras; y de aquí, al Gobierno: tales son las etapas graduales que recorre en su vida el joven corto de escrúpulos, dispuesto a jugar al pro y al contra con todos los problemas» ${ }^{13}$.

Es inquietante esta imagen de estudiantes que se dejan guiar simplemente por la realidad circundante, como un obrero maneja su máquina, sin preocuparse de saber cómo ha sido construida; pero al mismo tiempo no es menos inquietante la imagen de profesores que enseñan siguiendo las sendas marcadas por los diversos tipos de positivismo jurídico existentes, sin molestarse en comprobar el valor de estas sendas. Por esta razón, — termina concluyendo Villey, coincidiendo plenamente con el diagnóstico que hacen los krausistas de su época-, nuestros enormes tratados de "dogmática jurídica», nuestras clases universitarias, nuestros sistemas, no son sino colosos con pies de barro, hermosas construcciones edificadas sobre una base de arena movediza e inestable.

En la línea de Ihering y Posada, Giner viene a plantear con esta crítica la necesidad de reflexión sobre los fines del derecho, pues éstos son determinantes para elegir los medios y la metodología del Derecho. De hecho, hoy en día es casi imposible imaginar un jurista que no sea al propio tiempo filósofo del Derecho, a menos que esa sociedad o ese jurista pretendan desviar deliberadamente su atención de los problemas que de modo inevitable le plantea su actividad cotidiana. Lo que los krausistas nos dirían es, dado que ningún jurista, científico o especialista, tiene la posibilidad de escapar, de modo duradero, a una toma de posición más allá de su propia ciencia, no cabe realmente otra actitud razonable para el jurista que la de hacer lo más honestamente posible aquello que no tiene libertad de no hacer. Más vale pues que los juristas hagan conscientemente filosofía, en lugar de hacerla inconscientemente, ya que su trabajo teórico y su experiencia práctica, de modo inevitable, les llevará a hacerla. Es, por lo tanto,

13 Giner De los Ríos, F., «Notas Pedagógicas. Sobre el estado de los estudios jurídicos en nuestras universidades», en: Boletín de la Institución Libre de Enseñanza [BILE], XII, tomo I, 1888 , p. 23. 
más inteligente tomar partido con lucidez, que hacerlo bajo el impulso de impresiones y sentimientos no controlados.

Hacerse consciente de ese sistema de valores que está presente en su ciencia, comprometerse y declararse a favor de alguna visión del mundo, por parcial y provisional que ésta sea, tal sería la razón de ser de la filosofía del derecho y de la sociología krausista.

Así, como se ha tenido ocasión de señalar, si bien es cierto que Giner define el Derecho y la Moral como ciencias éticas formales, éstas presuponen siempre la ciencia ética material del bien y bienes de la vida. En palabras de Julián Sanz del Río, «la ley del derecho, [...] se contiene en y bajo la ley del bien moral» ${ }^{14}$. La separación del elemento formal de su contenido, no entrañaría, como vemos, una posición practicable para los krausistas, pues la función normativa del Estado siempre actúa para algo, recibiendo de la determinación del fin la orientación de su función: «El fin del Estado es, como ya se ha considerado antes, el Derecho en todo su pleno sentido, como derivado del fin ético de la humanidad, y en constante relación con él $»^{15}$.

Ahora bien, la determinación de este fin ético para la infusión moral en el Estado, no viene, a juicio de Giner, de arriba abajo, esto es, del poder a los súbditos, sino, antes al contrario. Frente a «las abstracciones de gabinete propias del liberalismo moderno representadas en Kant por tan eminente manera ${ }^{16}$, Giner considera que el derecho viene de abajo arriba, «siendo el derecho exterior a modo de un producto, de un fruto natural, que brota de las raíces mismas de la vida ${ }^{17}$. La determinación del contenido de la acción del Estado, esto es, de su fin, vendría a ser obra de la sociedad y tendría su cimiento y estimulante en la cultura, de ahí el papel decisivo que Giner otorga a la opinión pública. El Estado, por su parte, contribuiría a producir la cultura, o sea, el sentido general de la vida del pueblo en relación con su ideal concreto en una síntesis de sinergias sociales: «el Estado, en su relación final, entraña la expresión jurídica circunstancial de la cultura misma, o sea el ideal de vida; y su acción se distingue por el modo como actúa» ${ }^{18}$.

La definición gineriana del Derecho es, pues, la de una ciencia ética formal que presupone la ciencia ética material del bien/es. Sus críticas a la fórmula abstracta del derecho conducen, en última instancia, al reconocimiento del fundamento de los valores ético-jurídicos que reciben su contenido material del sistema de fines radicales humanos.

Este es uno de los rasgos caracterizadores de la actual coyuntura jurídica y política, v. gr., la tendencia hacia la moralización del orden constitucional

14 SAnz del Río, J., «El Derecho y el Estado, según Krause», en: BILE, VI, tomo II, 1882, p. 270.

15 Ahrens, E., Enciclopedia Jurídica, op.cit., t. III, 1880, pp. 310-311.

16 Giner de los Ríos, F, Resumen de Filosofía del Derecho. Madrid, Tomo II, OO.CC, t. XIV, 1926, p. 139.

17 Ídem.

18 PosadA, A., «El fin del Estado», en: BILE, XXXIX, tomo I, 1915, pp. 141-142. 
en la recepción de determinados valores éticos ampliamente reiterados en el constitucionalismo, así como una nueva tendencia a des-formalizar el Derecho y a propiciar una nueva síntesis de los principios del Derecho con los valores morales en busca de un ethos universalista. La tarea de ofrecer un enfoque adecuado a ese dilema constituye uno de los grandes retos de la cultura jurídica y humanista contemporánea.

Valga pues este breve excurso para situar las tesis del krausismo en el diálogo que mantuvieron con diferentes tradiciones de pensamiento en el contexto europeo y su reivindicación de unos principios de justicia, que no sólo nos resultan enormemente útiles para entrar en el análisis y revisión que los krausistas hacen del formalismo jurídico, sino que también nos pueden ayudar a contextualizar y comprender su propuesta de un derecho internacional basado en nociones moralmente densas como las del armonicismo y la solidaridad, que trataremos de abordar en el siguiente apartado.

\section{CRÍTICA AL NACIONALISMO IDENTITARIO, BELICISTA E IMPERIALISTA}

En torno a los últimos años del siglo XIX y las primeras décadas del siglo XX se produce en Europa un movimiento de los nacionalismos identitarios en estado de revancha, que trajo consigo una mitología instalada en el lugar donde debería hallarse la razón, y que estuvo a punto de arrojar nuestra civilización al sumidero de la feroz estética de los pueblos elegidos. En efecto, la universalidad reivindicada por la filosofía racional de la Ilustración fue desapareciendo gradualmente en los grandes relatos de la filosofía de la historia y fue reemplazada por los particularismos románticos que apostaban por la singularidad de la cultura y por una defensa casi visceral de lo irracional por encima de toda consideración racional, haciendo primar así el sentimiento frente a la razón ${ }^{19}$.

El Derecho era, sobre todo, expresión de este «espíritu nacional» (Volksgeist) que emanaba de la idea romántica de la colectividad considerada como organismo. El peligro teórico que llevaba consigo esta sustanciación de lo colectivo en una conciencia o espíritu colectivos es la facilidad con que ciertos sectores de la sociedad o ciertos individuos se arrogan interesadamente el derecho a constituirse en los intérpretes, líderes o guías únicos y más fidedignos (no otra cosa significa el término Führer) en los que se personifica esa conciencia nacional. Este dominio de la cultura y de la identidad étnica de la nación en la codificación de las leyes, que llegó a colonizar por completo el sistema jurídico, facilitaba indudablemente todo tipo de manipulaciones interesadas, de tal

19 «Cada pueblo es una individualidad portadora de un espíritu singular, que es la fuente de todo lo que constituye la cultura de ese pueblo: el lenguaje, el arte, las costumbres, el Derecho. Este no es el producto de la razón ni de la voluntad; no es una pura obra intelectual ni menos un fruto del arbitrio; su fuente está en la convicción jurídica del pueblo, que es una intuición emocional de lo que debe ser la regulación de la convivencia humana». Legaz LACAmBra, L., Filosofía del Derecho. Barcelona: Ed, Bosch, 1953 (2ª ed., 1961), p. 98. 
manera que todo aquel que discrepara del programa político del Führer podría ser automáticamente considerado como auténtico enemigo de la nación. En tal modelo, el ciudadano quedaba pues anulado por ser considerado moralmente inferior a una comunidad que exige silenciarlo para hablar en su nombre.

Su planteamiento básico era pues la reivindicación del componente nacional y de lo particular frente a lo universal, todo lo cual venía, en última instancia, a legalizar las divisiones étnicas y culturales, que producían rigideces inútiles e inicuas en la política local, nacional e internacional.

Ese desprecio de toda fundamentación universal no ocultaba en el fondo sino un rechazo por todo aquello que pudiera ser sospechoso de haberse inspirado en las ideas ilustradas, cuyas formas políticas liberales clásicas eran manifiestamente incoherentes e incompatibles con las tesis del nacionalismo imperialista y la sociedad que pretendía organizar ${ }^{20}$.

Todo ello se desarrolló además en una coyuntura económica marcada por la contracción finisecular del capitalismo europeo, la cual encontró una alianza con esta oleada del nacionalismo imperialista y su intensa búsqueda de mercados.

En este contexto tan delicado se sitúan las acerbas críticas de Giner y Posada a la proliferación de estas doctrinas europeas del nacionalismo imperialista. Sus impugnaciones al nacionalismo se van a dirigir fundamentalmente a remediar ese sesgo conflictivo que la exaltación imperialista fue generando en toda Europa, y en particular en España, durante estas décadas.

Los krausistas españoles tuvieron pues un papel muy importante en las duras críticas que, desde presupuestos fundamentalmente internacionalistas, realizaron a la orientación imperialista que se ocultaba bajo las doctrinas nacionalistas del decisionismo y el totalitarismo político.

Esta postura pacifista y la tendencia armonicista característica del krausismo fueron defendidas con especial ardor por Adolfo Posada, quien, durante la guerra europea exhibió siempre un antibelicismo incondicional, gracias al cual acertó a dar una visión muy actual del problema de la guerra.

En consecuencia, Posada se enfrentó expresamente a teorías como la de Carl Schmitt, para quien la esencia de la relación política se mantiene en la referencia a una contraposición o lucha concreta, y cuya última consecuencia es un agrupamiento del tipo amigo-enemigo. En esta conocida teoría de Schmitt, lo político es una conducta determinada a partir de la posibilidad real y efectiva de lucha, más concretamente, de guerra abierta o revolución. La guerra sería pues el pre-supuesto, en tanto posibilidad real permanentemente existente, que define la acción y el pensamiento político. Esta posibilidad real del combate - según afirma Schmitt- refiriéndose tanto a la guerra civil como a la guerra

20 "The national became identified with the universal, and the irrational collective spirit

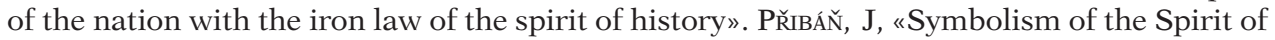
the Laws: A Genealogical Excursus to Legal and Political Semiotics», en: International Journal for the Semiotics of Law, Vol. 22, n 2, p. 187. 
entre unidades organizadas de pueblos (Estados o Imperios), siempre tiene que estar presente para que pueda hablarse de política:

«Porque recién en el combate real queda demostrada la consecuencia extrema del agrupamiento político en amigos y enemigos. Es desde esta más extrema posibilidad que la vida del ser humano adquiere su tensión específicamente politica. Un mundo en el cual la posibilidad de un combate estuviese totalmente eliminada y desterrada, un globo terráqueo definitivamente pacificado sería un mundo sin la diferenciación de amigos y enemigos y, por lo tanto, sería un mundo sin política. Podría existir en él toda una variedad de interesantes contraposiciones, contrastes, competencias e intrigas de toda clase; pero razonablemente no podría existir una contraposición en virtud de la cual se puede exigir del ser humano el sacrificio de la propia vida y en virtud de la cual se puede autorizar a seres humanos a derramar sangre y a dar muerte a otros seres humanos $»^{21}$.

Posada rehusó y criticó con fuerza estos planteamientos de Schmitt y su caracterización del medio político como el espacio para esos combates concretos; en su lugar, lo que mantuvo Posada en todo momento y hasta los últimos días de su vida, fue la defensa de un mundo más humano, desarmado y educador, la cual era la única respuesta coherente con la tendencia armonicista del krausismo que había aprendido de su maestro, Giner de los Ríos:

«Y porque los problemas de la guerra y los de la etapa presente de paz enconada parecen hallar en los ideales de Giner la solución más armónica y elevada. Las doctrinas que Giner combatió han dado fruto de tragedia. Los horrores de la lucha, el nacionalismo agresivo de esta tregua imperialista y sus ensayos de dictadura, se nutren con la idea hegeliana del poder absoluto del Estado nacional, a la cual Giner oponía la soberanía inviolable de individuos, familias y regiones y el supremo límite de una Sociedad de Naciones abarcando a la Humanidad entera ${ }^{22}$.

Es interesante comparar estas expresiones con la literatura europea de la época, pues nos muestran cómo en este contexto de enconadas disputas ideológicas, los krausistas mantuvieron posiciones decididamente liberales al conservar su fe en la razón y proponer una nueva vía política que, vista desde nuestra atalaya, se revela como más coherente, atractiva y libre que la que tomó Europa en estos años.

Sólo las masacres de inocentes a manos de proyectos totalitarios en los que se manifestaban los peores desequilibrios de una patología social, pudieron devolvernos el sentido de la orientación que habíamos perdido. Es, por lo tanto, importante constatar que, en un contexto histórico de grandes conflictos, los juristas y sociólogos provenientes del krausismo fueron coherentes y no variaron su ideario antibelicista ni sus esquemas de actuación.

21 Schmitt, C., El concepto de lo político. Texto de 1932 con un prólogo y tres corolarios, versión de Rafael Agapito. Madrid: Alianza editorial, 1999, p. 20.

22 Castillejo y Duarte, J., «Introducción», en: Giner de los Ríos, F. y Calderón, A., Resumen de Filosofía del Derecho. Madrid, Tomo I; OO.CC., t. XIII, 1926, p. VI. 
En resumen, en esta tesitura en que la ideología imperialista y belicista comenzaba a invadir Europa, y a su través, a España, los krausistas españoles adoptaron una postura realmente opuesta a lo que sería esa tendencia mayoritaria europea.

Esta impronta antiimperialista también está presente en su visión de la tendencia política unificadora de Europa y su concepción del derecho internacional como un proceso de crecimiento hacia la mundialización, que ya no se centraría meramente en pueblos, Estados o clases sociales, sino que, comenzando por el individuo, abarcaría armónicamente a todos los grupos sociales intermedios, los cuales son rebasados en un segundo momento hacia la unión mundial. En este sentido, es interesante subrayar la presencia de huellas antiimperialistas en el pensamiento ilustrado del krausismo español y en su modo concebir al Estado ${ }^{23}$.

Como se pondrá de manifiesto en el siguiente apartado al tratar del papel que tienen algunos krausistas en la formación de la Sociedad de Naciones, hay en su filosofía jurídica un fondo insobornablemente liberal, una clara vocación europeísta y una profunda fe en la cultura y en las posibilidades de un cambio social a través de un cambio ético del hombre individual, posiciones que no encuentran parangón en la época y que, a pesar de haber encontrado gran extrañeza y resistencia en su época, han pasado a ser hoy patrimonio común de la filosofía del derecho de nuestro tiempo y de las aspiraciones de nuestra sociedad.

\section{Los Catorce puntos de Wilson y la Sociedad dE Naciones}

La teoría organicista de la sociedad formulada por la escuela armónica de Krause parte de una concepción de soberanía política, en la que ésta aparece distribuida de modo orgánico y plural entre sus miembros, los cuales, a modo de círculos concéntricos, tienen su origen en el microcosmos del estado individual, denominado también república interior del hombre ${ }^{24}$, donde el individuo constituye un Estado soberano autónomo e inviolable en su vida y derecho interior. Pero los individuos son miembros también de Estados superiores compuestos como la familia (el Estado doméstico), el Estado gentilicio, Estado municipal, provincial, nacional, étnico, continental hasta llegar a la nación y a la comunidad universal de Vida, que fundamenta un derecho cosmopolítico. Como se ha señalado, con esta teoría social el krausismo promueve la universalización de los derechos del hombre y los principios de un Derecho

${ }^{23}$ Sobre cómo se trató de impedir la legitimación de la colonización imperial con base en algunas tesis krausistas, véase: Antolín Sánchez Cuervo, «El krausismo español ante la pervivencia del colonialismo», en: Solar, $n^{\circ}$ 4, año 4, 2008. Lima, pp. 81-99.

24 La teoría organicista de la sociedad formulada por Krause tiene cierta impronta platónica, como puede apreciarse en su doctrina del microcosmos del Estado individual, también denominada república interior del hombre en Platón (República, 568b). 
Internacional que constituiría el círculo superior común al que los anteriores deben subordinarse:

«...las personas y Estados correspondientes se hallan solidariamente relacionados entre sí, siendo cada persona total un organismo de todas las más limitadas que contiene (v. g., la familia, organismo de individuos; el municipio, de familias, etc.); y penetrando a la vez, bajo ser unas, en las sociedades especiales, en cuyo seno cumplen cada fin de la vida: así, por ejemplo, la Iglesia ó la Sociedad científica pueden extenderse (y aún lo exige imperiosamente la razón) sobre todo límite local, nacional, etc., los cuales sólo debieran subsistir en ellas como círculos interiores, sustantivos al par que armónicamente unidos entre sí y con el todo; por más que su respectiva constitución diste tanto todavía de ese ideal, verdadero Estado universal humano, a cuya realización tiene incesantemente la historia» ${ }^{25}$.

Puede apreciarse también la vigencia de las propuestas krausistas de reforma en el contexto europeo en la esperanza que Francisco Giner mantuvo toda su vida de que surgieran organismos superiores ante los cuales el Estado Nacional tendría que ceder parte de su soberanía, previendo así la gran organización internacional de ámbito universal, la Sociedad de Naciones, que por sólo cuatro años no llegaría a conocer. En sus textos queda recogida esta visión preclara de lo que debía ser el Derecho internacional:

«La acción del estado nacional se ejerce sólo como supletoria de más altos órganos y a falta de ellos. [...] suplirá también interinamente la falta de un verdadero Estado internacional, órgano de aquel derecho cosmopolítico que han entrevisto en todos tiempos los más grandes pensadores estadistas». Más adelante añade Giner: «[el Estado Nacional] ejerce funciones que no le corresponderían si se hallasen constituidas en un sistema verdaderamente regular y positivo las relaciones internacionales» ${ }^{26}$.

A pesar de que la política exterior de España durante este periodo histórico ha tenido un carácter secundario para algunos historiadores ${ }^{27}$, consideramos reseñables los notables avances que se producen en el área del pensamiento y la reflexión filosófico-jurídica gracias a determinados pensadores krausistas que, como Giner, acertaron en dar con este tipo de formulaciones.

Pocos años después, un krausista y discípulo de Giner, Adolfo Posada, vio germinar la acariciada fórmula de la Sociedad de las naciones gineriana, la cual entrañaba no sólo el supuesto indicado del apaciguamiento de todo

25 Giner de los Ríos, F. y Calderón, A., Prolegómenos del derecho. Principios de derecho natural, sumariamente expuestos. Madrid, OO.CC., t. I, 1916, p. 184.

26 Giner De los Ríos, F., «El Estado Nacional», en: BILE, IV, tomo I, 1880, pp.168 y 173.

27 «el tema de la política exterior de España durante el largo siglo que media entre el Congreso de Viena (1815) y el comienzo de la guerra de España (1936), parece tener un carácter tan secundario, tan provinciano y tan pequeño, que nosotros mismos, españoles, venimos sintiendo desde hace varias décadas la tentación de dejarlo en paz; de consagrar nuestro trabajo de historiadores a otras épocas más brillantes». Jover ZAMORA, J. M., España en la política internacional, Siglos XVIII-XX. Madrid: Marcial Pons, Ediciones de Historia, 1999, p.111. 
nacionalismo agresivo, sino la afirmación plena del espíritu democrático, desde su base —en el individuo como ciudadano - hasta los organismos superiores del gobierno nacional e internacional. Un espíritu democrático que había sido vislumbrado ya por Giner, al hacer residir su base y soporte en el debido respeto a la personalidad humana.

Dicho enfoque krauso-gineriano es el que retoma Adolfo Posada, quien no sólo reflexiona sobre la formación de la Sociedad de Naciones, sino que también vaticina algunas de las dificultades principales a las que deberá de hacer frente una vez constituida, como la del llamado déficit democrático:

«¿cómo hallar, en efecto, una forma política democrática, de tal amplitud, flexibilidad y cimiento, que sirva para dotar a la Sociedad de las naciones de instituciones netamente representativas? ¿Cómo idear una constitución popular, a través de la que pudieran influir, y ejercer su acción decisiva, las naciones mismas como tales, y no los gobiernos con sus hombres, representativos hoy de las máximas desconfianzas entre los pueblos? ¿Cómo borrar el carácter oligárquico de esa Sociedad de disimulados imperialismos? Esa, esa, querido amigo, será la suprema dificultad, aun después de resolver tantas otras como se oponen a que esta Sociedad de naciones sea la Sociedad de "todas" las naciones»" ${ }^{28}$.

Hacia el final de la Primera Guerra Mundial, Adolfo Posada fija su atención en el famoso discurso de los Catorce Puntos del presidente de los Estados Unidos, Woodrow Wilson, cuya obra ya había seguido de cerca con anterioridad ${ }^{29}$. En el discurso se hace un llamado a las naciones europeas en conflicto para que detengan el fuego y den paso a la reconstrucción del continente. Lo que se pedía era una asociación general de naciones, constituida mediante determinados pactos, con el propósito de garantizar mutuamente la independencia política y la integridad territorial tanto de los Estados grandes como de los pequeños. Se estaba alumbrando así la creación de un nuevo orden mundial que, según los auspicios más optimistas, permitiría desvanecer el fantasma de la guerra en todo el planeta ${ }^{30}$.

28 Posada, A., Actitud Ética ante la Guerra y la Paz, Madrid, Caro Raggio Editor, 1923, p. 152.

29 Posada encontró una de las concepciones americanas del Estado mejor construidas en el libro El estado: elementos de política histórica y práctica, Madrid, V. Suárez, 1904, 2 vol., obra escrita por Wilson, W. cuando todavía era profesor en Princeton, y que Posada comentó y tradujo al español. Vid. Posada, A, «El fin del Estado», en: BILE, XXXIX, tomo I, 1915, p. 142.

30 Ciertamente, los auspicios fueron demasiado optimistas. Como nos ha revelado la historia, el papel que desempeña Estados Unidos durante el siglo xx resulta paradójico puesto que el inspirador intelectual y político del nuevo orden de la posguerra, el presidente norteamericano Wilson, no logró incorporar su propio país en la Sociedad de Naciones. En efecto, a pesar de haber sido capaz de articular grandes propuestas para una nueva normativa internacional y de ser el principal promotor de normas e instituciones multilaterales del mundo, sin embargo, EEUU se ha negado sistemáticamente a atarse mediante compromisos y obligaciones institucionales. En rigor, no se ha comprometido excesivamente con dicho 
Wilson invitaba así a los pueblos europeos a «salir del "estado de naturaleza” para constituirse en sociedad civil: la sociedad civil de las naciones, cambiando el régimen de luchas, —afirma Posada - en que todo pueblo es lobo para los demás pueblos, en un régimen de paz basado en el respeto al derecho, o a los derechos, de todos ${ }^{31}$.

Entre los artículos de esta gran Carta de las Naciones en la que, según Posada, «la humanidad por la vez primera hace escuchar su voz y su derecho eterno en el Estado» ${ }^{32}$, destacamos las doctrinas del presidente Wilson que quizá han tenido mayor desarrollo en la filosofía krausista: aquellas que tienen que ver con la valorización ética de la política y los principios de los derechos humanos en un momento histórico en que se cernían sobre la humanidad las terribles amenazas del nazismo, el fascismo y el holocausto, en particular: el Art. 6. ${ }^{\circ}$, que establece que el ideal del régimen futuro no consiste en un equilibrio de potencias, sino en una comunidad de potencias; no en rivalidades organizadas, sino en una paz común organizada.

El Art. 9. ${ }^{\circ}$ de Wilson indica que la paz de las naciones sólo puede ser mantenida por la fuerza superior organizada de la humanidad, una expresión que participa tan claramente del espíritu krausista que su redacción pudiera confundirse o atribuirse a la del propio Krause.

La lectura del libro de Wilson resultó pues harto significativa para Posada, no sólo por constituir un llamamiento a la actividad reformista nacional y al análisis de la realidad europea en la que se encontraba inmerso, sino también una demostración de la fecundidad de las concepciones krauso-ginerianas, cuyos principios universales referidos al gran «metamarco» de valores de los derechos humanos encontraba profundas afinidades con las conclusiones éticas y la práctica política de Wilson:

«Los que empezamos a filosofar, o si queréis, a reflexionar, recorriendo el Ideal de la Humanidad de Krause, traducido y comentado por Sanz del Río, tenemos que sentirnos edificados al ver cómo parecen tomar forma histórica aquellos anhelos y esperanzas, expuestos en el hermoso libro por un filósofo que, al soñar, parecía presentir la solución con que habría de brindarse, al fin, a la humanidad entera. [...] Y de ahí por qué relacionábamos, en nuestra emoción, la voz de Wilson con el Ideal de la Humanidad. Oiga un momento el lector lo que dice el libro: háblase en él de la formación ideal de los Estados: pero los Estados de Krause no son como el Estado dominador de Treitschke: son como el de nuestro Giner: Estado-autonomía [...]. Los Estados de Krause son círculos o esferas de asociación humana, mantenidos merced a

orden, como se ha hecho visible actualmente desde la guerra de Irak, que ha conllevado una crisis de legitimidad actual de tal envergadura, que ha sido interpretada incluso como muestra del estrepitoso fracaso en la creación de un nuevo orden internacional tras la guerra fría; pero esto ya desborda el tema de este artículo. Vid. Javier Álvarez, «Contemporary International Law: an «Empire of Law» or the «Law of Empire», trad. Delia Manzanero, en: Bajo Palabra. Revista de Filosofía. Madrid, II Época, nº 4, 2009, pp. 211-236.

31 Posada, A., Actitud Ética ante la Guerra y la Paz, op.cit., p. 68.

32 Ibíd. 104. 
la existencia de conciencias jurídicas comunes: y la escala de los grados no termina en las naciones, en el Derecho Natural de Giner: la visión penetrante - poética-del porvenir prevé que los Estados de los pueblos han de unirse, y que, al fin, formarán un Estado, que ahora acaricia y siente Wilson» ${ }^{33}$.

En efecto, encontramos una importante semejanza de los objetivos defendidos por la fuerza impulsora de los ideales de paz del mensaje de Wilson, con las tesis de mejoramiento progresivo de la ética colectiva que proponen los krausistas, y de ambas, con el nuevo orden kantiano europeo de una comunidad perpetua pacífica de todos los pueblos de la Tierra. Sus programas convergen en una concepción del derecho cosmopolita compartida, según la cual, junto a la ciudadanía estatal, existe también la que suele denominarse una ciudadanía cosmopolita que se deriva de la condición de persona y a la que se anudan trascendentales derechos humanos ${ }^{34}$.

Sus líneas de acción también confluyen en sus apreciaciones de lo que debería ser objeto de impugnación en materia de derecho internacional; así pues, sus críticas se dirigen a la crisis europea generada por la exacerbación nacionalista, totalmente refractaria al surgimiento de una conciencia colectiva entre los europeos, y que desembocaría de forma brutal en la Primera Guerra Mundial, a la que Posada llamó, muy significativamente, como gran guerra «civil» de la humanidad entera por antonomasia.

Sin embargo, el legado de esta primera guerra europea incubaba los peores presagios de que las viejas adhesiones totalitarias iban a mezclarse con nuevas formulaciones políticas (nacionalismo, imperialismo-colonialismo, fascismo, comunismo,...), empeorando el clima político y dejando el sistema europeo profundamente inestable, con un alto nivel de conflictividad políticas y territoriales, lo que, en última instancia, condujo a la destrucción de todos los valores de la civilización europea anclados en la Ilustración ${ }^{35}$.

Dados el gran fracaso de sus previsiones acerca del curso de la historia y del derecho internacional positivo y el escaso efecto que tuvo como «acto» de pacificación en una tradición impregnada de la maquiavélica guerra de todos contra todos, la doctrina político-jurídica de Wilson para la paz futura fue finalmente tildada — especialmente por foros esclavizados por el pragmatismo- de utopía ingenua y de excesivo idealismo.

Las mejores intenciones de Wilson y de los creyentes en la generosa utopía del pacifismo natural de los pueblos, iban pues a sufrir, en su confrontación

33 Ibíd. 101 y 103.

34 Los principios del cosmopolitismo y la concepción del ciudadano del mundo (Weltbürger) son vistos por Kant como la mejor representación de la igualdad moral y de la dignidad de la persona en la «comunidad universal» $y$, en tal sentido, pueden servir de base a un profundo rechazo del colonialismo. Cfr. Held, D., Cosmopolitismo. Ideales y realidades, trad. Dimitri Fernández Bobrovski, Madrid, Alianza Editorial, 2010, pp. 49-ss.

35 Forner Muñoz, S., Comprender Europa. Claves de la integración europea, Madrid, Biblioteca Nueva, 2010, pp. 48-50. 
con la realidad, el más rotundo revés como instrumento para asegurar la estabilidad territorial, política y económica de Europa tras la Primera Guerra.

Según Posada, la lamentable ineficacia e impotencia de la Sociedad de Naciones para hacer respetar un mínimo la paz mundial vino dada por haber sido «elaborado ese derecho más como obra de políticos y juristas que como labor de pueblos, a espaldas de éstos, sin despertar en ellos aquella comunidad de vida que es condición necesaria y esencial para que se produzca el derecho eficaz. La guerra vino, y al estallar negó casi totalmente las normas fundamentales del derecho internacional, porque en el momento oportuno faltó la conciencia "supernacional” con la fuerza moral capaz de reaccionar contra las violencias iniciales ${ }^{36}$. Su fracaso vendría explicado por prescindir de una dimensión sociológica que procurase una mayor cercanía a esa realidad social y por no tener en cuenta las realidades concretas sobre la que se aplicaron determinados principios ni los efectos perversos que esa aplicación podría desencadenar.

Por fortuna, a pesar de este estrepitoso fracaso del ideal krausista, la historia nos confirma que, aunque fuera arduamente, se estaban ya confeccionando y asentando las bases de una paz con pretensiones de universal; que, aunque de modo confuso y fragmentario, las democracias empezaban a reclamar más estabilidad, y que, aunque tuviera que atravesar un proceso lento y laborioso, se había formulado ya un Estatuto para la Sociedad de Naciones. Esto marcó desde luego un hito importante, por lo que no se puede entender como absoluto el fracaso del sueño utópico de la Sociedad de Naciones de Wilson, ni del proyecto krausista de un estado humano universal:

«El mayor interés de la Sociedad de Naciones, [...] no está sólo en cuanto aquélla pueda representar —y en parte representa ya- en la elaboración del nuevo orden internacional, y como dificultad suprema contra la violencia de las guerras, sino en lo que la consolidación de una Sociedad de Naciones puede significar, desde el punto de vista de la realización de lo que llamamos superliberalismo, y que vendría a ser la garantía suprema del liberalismo» ${ }^{37}$.

Al fin y al cabo, no sería posible entender esta voluntad europeísta original y lúcida del krausismo español, que destaca entre cuantas manifestaciones de este orden cabe señalar en el marco de la cultura española contemporánea, como frutos de la modernidad sin su carácter utópico ${ }^{38}$. Aunque aquí sería mejor

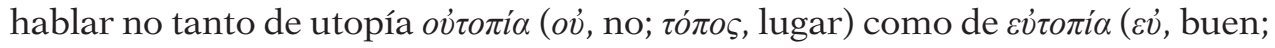

36 PosadA, A., Actitud Ética ante la Guerra y la Paz, Madrid, Caro Raggio, 1923, pp. 84 y 153-54.

37 Ibid, p. 13.

38 Recuperamos aquí la teoría crítica con que iniciábamos este ensayo y la relación que establecíamos con la necesaria reflexión que reclamaban los krausistas sobre los fines del derecho: «Nuestra misión actual es, antes bien, asegurar que en el futuro no vuelva a perderse la capacidad para la teoría y para la acción que nace de esta, ni siquiera en una futura época de paz, en la que la diaria rutina pudiera favorecer la tendencia a olvidar de nuevo todo el problema. Debemos luchar para que la humanidad no quede desmoralizada para siempre por los terribles acontecimientos del presente, para que la fe en un futuro feliz de la sociedad, 


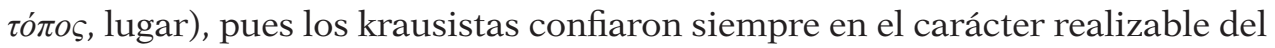
Ideal de la Humanidad y en la integración europea, en su impulso por hallar sociedades más humanas y solidarias, otorgando así dinamismo a la idea clásica de modernidad y permitiéndole una ampliación de sus bases democráticas, a modo de una especie de sistema reflexivo de la modernidad por la cual ésta ha ido mejorando constantemente hasta nuestros días, enfrentándose críticamente a la realidad para no resignarse con lo injusto que hay en ella ${ }^{39}$.

\section{Conclusión}

Por lo tanto, puede concluirse que, a pesar de haber dado en tierra con muchos de sus ideales ilustrados, los krausistas no cejaron en sus empeños humanitarios y confiaron en que sus ideales utópicos concretos cumplirían su labor en las generaciones futuras, tal y como afirma con convicción Posada:

«¿Utopía?, quizá; pero ya sabes que sin utopías la humanidad estaría en las cavernas. La utopía de hoy puede ser la realidad de mañana, o de pasado mañana». [...] «Se podrá oponer que somos una minoría. "Una golondrina no hace la primavera", sin duda; pero puede decirse: "Una golondrina anuncia que la primavera vuelve"». «La manifestación de hoy es un síntoma que debe incitarnos a pensar que no serán vanos nuestros esfuerzos y que un día se establecerá una paz duradera entre Francia y Alemania» ${ }^{40}$.

De hecho, sus puntos de vista principales se vieron confirmados y muchas de sus propuestas pudieron aplicarse a determinadas reformas nacionales y a orientar la tarea organizadora de los políticos, por ejemplo, en el reconocimiento y la internacionalización jurídico-positiva para la protección de los derechos humanos, que experimentó un gran avance desde aquel entonces; sus hitos principales van desde el Tratado de Versalles de 1919 del que surge la Sociedad de Naciones, hasta la Declaración Universal de los Derechos Humanos de la ONU de 1948 en cuyo texto se expresa este carácter de «ideal común por el que todos los pueblos y naciones deben esforzarse»; sin olvidar el Consejo de Europa creado en Londres en 1949, con sede en Estrasburgo, y que -en palabras de Truyol y Serra- es «la expresión de la idea europea occidental de la democracia política ${ }^{41}$.

A pesar de estos progresos, la evocación emocionada que hace Adolfo Posada de los pasajes del Ideal de la humanidad para la vida de Krause continúa

en un futuro de paz y digno del hombre, no desaparezca de la tierra». HorkHEIMER, M., Teoría crítica, op. cit., p. 299.

39 Véase refrendada esta postura, en términos filosóficos, por Julián Sanz del Río: «Nota de Sanz del Río: 2) Una ley de la historia humana, como parte de la historia universal», en: Ideal de la Humanidad para la vida, C. Chr. F. KRAuSE. Con introducción y comentarios por D. Julián Sanz del Río. pp. 236 y 237.

40 Posada, A., Actitud Ética ante la Guerra y la Paz, op. cit., pp. 150, 159-160.

41 Truyol y Serra, A., Los derechos humanos, Madrid, Tecnos, 1994, p. 43. 
siendo necesaria, pues hoy en día seguimos sin alcanzar ese estatuto jurídico de la Humanidad con el que soñaban Giner y Posada. En cualquier caso, es importante dejar constancia de que, gracias a los ideales de racionalidad y progreso del iusnaturalismo crítico krausista, se ha podido constituir y dotar de significado a ese largo y laborioso proceso de la positivación jurídica de los derechos humanos fundamentales. De ahí que sea importante estudiar estos presupuestos filosóficos y aspiraciones políticas que nos ofrece la filosofía del derecho krausista, pues son de gran utilidad para comprender las motivaciones que sirvieron de base a su plasmación ulterior en las normas positivas dentro del marco europeo; sirviendo quizá en ocasiones de acicate para una más rápida evolución de los instrumentos surgidos de las Naciones Unidas o como modelo para el desarrollo de este proceso en otras regiones.

En definitiva, puede afirmarse que el hecho de que la protección de los derechos humanos fundamentales haya dejado de ser una cuestión doméstica supeditada al mero arbitrio de los Estados para pasar a convertirse en un auténtico problema internacional y humano, supone, desde el punto de vista de la fundamentación de los derechos humanos, una vuelta a la reivindicación de su carácter universal y supraestatal, donde la filosofía del derecho krausista ha hecho sus mayores contribuciones y cuyo legado continúa representando un reto para las sociedades actuales.

Universidad Pontificia Comillas, Madrid

Delia Manzanero

deliadelos@hotmail.com

[Artículo aprobado para su publicación en noviembre de 2013] 